\title{
Modeling of Amphoteric Heavy Metals Solubility in Stabilized/Solidified Steel Foundry Dust
}

\author{
Iñaki Fernández-OImo, * Cristina Lasa, María Angeles Lavín, and Angel Irabien \\ Departamento Ingeniería Química y Química Inorgánica, ETSII y T, Universidad de Cantabria, Santander, Spain.
}

Received: August 21, 2007

Accepted in revised form: February 25, 2008

\begin{abstract}
The influence of $\mathrm{pH}$ on the leaching of metals from waste materials can be described by geochemical and empirical models. These equations may be integrated into dynamic leaching models in order to describe the longterm behavior of waste-derived forms or they can be used to predict the concentration of metals in equilibrium leaching tests at a given $\mathrm{pH}$. The aim of this work is to describe the equilibrium concentration of the main metals $(\mathrm{Zn}, \mathrm{Pb}$, and $\mathrm{Cr}$ ) contained in untreated and stabilized/solidified (S/S) electric arc furnace dust (EAFD) using experimental data obtained from a $\mathrm{pH}$-dependence leaching test (acid neutralization capacity, ANC). EAFD is a hazardous waste generated in steel factories. Steel foundry dust coming from an electric arc furnace was characterized by acid digestion, $x$-ray fluorescence $(\mathrm{XRF})$, and x-ray diffraction (XRD). The waste mainly contains $\mathrm{Zn}$ and $\mathrm{Fe}$, which were identified in zincite and zinc ferrite phases. $\mathrm{Pb}$ and $\mathrm{Cr}$ were also detected at lower concentrations. Cement/EAFD formulations ranging from 7 to $20 \%$ dry wt of cement were prepared and the ANC leaching test was performed. The amphoteric behavior of $\mathrm{Zn}, \mathrm{Pb}$, and $\mathrm{Cr}$ was described by the geochemical model Visual MINTEQ and by an empirical model developed for these metals. Zinc and lead solubilities were well described by both models; however, Visual MINTEQ failed to describe the chromium behavior quantitatively.
\end{abstract}

Key words: waste disposal; electric arc furnace dust; stabilization; heavy metals; leaching; solubility

\section{Introduction}

T HE LEACHING OF CONTAMINANTS from waste-derived forms involves complex mechanisms which take into account the dissolution/precipitation, adsorption/desorption, or oxidation/reduction reactions together with transport of dissolved ions in the liquid phase inside the waste material. The dissolution of solid phases from waste materials can be instantaneous or kinetically controlled. When instantaneous dissolution of contaminants is produced, a linear relationship between the concentration of immobile and mobile species can be applied (Côté et al., 1987):

$$
C_{i m}=K_{d} C_{m o}
$$

$C_{m o}$ represents the equilibrium concentration of the dissolved contaminant. This equilibrium concentration is $\mathrm{pH}$ dependent for most metals usually contained in waste forms.

When dissolution is kinetically controlled a simple first-

*Corresponding author: Departamento Ingeniería Química y Química Inorgánica, ETSII y T, Universidad de Cantabria, Avda Los Castros s/n 39005, Santander, Spain. Phone: +34 942 201586; Fax: +34 942 201591; E-mail: fernandi@unican.es order kinetic expression is given by equation (2) (Côté et al., 1987; Maisse and Pousin, 1997):

$$
v=k\left(C_{M}-C_{m o}\right)
$$

Where $v$ denotes the rate of dissolution of contaminant and $C_{M}$ the equilibrium concentration; when the dissolution reaction is fast, the concentration of mobile species is very close to the equilibrium concentration, which is the maximum concentration of contaminant that can be achieved at specified conditions (at a given $\mathrm{pH}$ ).

Thus, equilibrium models that consider the influence of $\mathrm{pH}$ on the solubility of metals are required for the solution of dissolution/transport dynamic leaching models developed to describe the long-term behavior of waste-derived forms. In addition, such equilibrium models can be used to estimate the concentration of metals at a given $\mathrm{pH}$ in compliance leaching tests performed under equilibrium conditions, such as the European EN12457 leaching test or the USEPA-TCLP test. The resulting $\mathrm{pH}$ depends on the acid neutralization capacity of the waste and the acidity/alkalinity of the leachant used in the test.

Together with compliance leaching tests, basic characterization tests which account for the influence of key factors on leaching of contaminants should be carried out accord- 
ing to the Landfill Directive (European Commission, 1999). The acid neutralization capacity (ANC) test is a $\mathrm{pH}$-dependent leaching test that has been considered as one of the basic characterization tests in the EU. This test can be used to generate experimental points of metal concentration at equilibrium conditions against leachate $\mathrm{pH}$.

Electric arc furnace dust (EAFD) is one of the main wastes generated in the steel industry; about 10-25 kg dust/t steel are separated from off-gas filtration units of electric arc furnace steel factories; it contains significant amounts of heavy metals such as $\mathrm{Zn}, \mathrm{Pb}, \mathrm{Cr}$, or $\mathrm{Cd}$. The $\mathrm{Zn}$ content may reach values of $30-40 \%$. This waste has been classified in the European Waste Catalogue as 100207 * "solid wastes from gas treatment generated from an electric arc furnace containing hazardous materials" and as K061 according to the U.S. EPA, which is defined as "emission control dust/sludge from primary production of steel in electric furnaces."

There are several options to manage EAFD: chemical stabilization prior to landfilling, vitrification, recycling by returning the dust to the furnace, and pyrometallurgical and hydrometallurgical processes for zinc recovery (European Commission, 2001); taking into account the Best Available Techniques Reference Document on the Production of Iron and Steel, dust recycling and zinc recovery are the most desirable options (European Commission, 2001); however EAFD is usually managed in Spain by stabilization/solidification (S/S) techniques and disposed of in landfills after treatment.

Some studies report the leaching behavior of untreated EAFD (Stegemann et al., 2000; Laforest and Duchesne, 2006). The leaching of metals from stabilized EAFD has also been widely reported in the literature from compliance leaching tests performed at short times and from leaching tests developed to account for the long-term behavior of the stabilized EAFD (Andrés and Irabien, 1994a, 1994b; Andrés et al., 1995; Fernández-Pereira et al., 2001; Fuessle and Taylor, 2004; Hamilton and Sammes, 1999).

Some information is available in the literature regarding the modeling of the solubility of heavy metals in EAFD matrices. Thus, Fernández-Pereira et al. (2001) showed a model based on the solubilization of zinc, lead and cadmium hydroxides under acidic and alkaline conditions for EAFD stabilized with coal fly ash; however, although the qualitative behavior was well described, the model overestimates the leaching of these metals. The leaching of chromium was not modeled, since the chromium concentrations did not show a clear relationship to the leachate $\mathrm{pH}$, probably due to the presence of $\mathrm{Cr}(\mathrm{VI})$ in the leachate (Fernández-Pereira et al., 2001). A different modeling approach is reported by Irabien et al. (2002): the concentration of cadmium, chromium, and lead in TCLP leachates obtained from stabilized/solidified EAFD was predicted using neural network modeling. Fernández-Olmo et al. (2007) studied the solubilization of Zn from EAFD using a geochemical model (Visual MINTEQ v. 2.31) and an empirical model.

Standard software based on geochemical models have been widely used to describe the solubility of heavy metals in soils (van der Sloot et al., 1996; Gustaffson et al., 2003; Dijkstra et al., 2004), wastes (Meima and Comans, 1997; Meima and Comans, 1998; Catalan Lionel et al., 2002), and cementbased stabilized wastes ( $\mathrm{Li}$ et al., 2001; van der Sloot, 2002; Coz et al., 2004). Many chemical equilibrium models are com- mercially available; some examples are MINEQL, SOLMINEQ, SIMUL, MICROQL, CHEAQS, MINTEQA2, SOLTEQ, HYDRA/MEDUSA, the Geochemist's Workbench, EQ3/6, PHREEQC, ECOSAT, VISUAL MINTEQ, and ORCHESTRA. Among these, MINTEQ A2 is probably the most common software to study the leaching of metals from soils and wastes.

The results obtained from geochemical models are discrete data of $\mathrm{pH}$-metal concentration. However, when chemical equilibrium models are needed to introduce into dynamic leaching models (coupled chemical/transport model), a mathematical equation is required. To solve this problem, some authors consider simple empirical models: the simplest case is to consider a polynomial equation, such as that used by Tiruta-Barna et al. (2004) for lead solubilization in a synthetic waste stabilized with cement:

$$
\log C_{M}=a_{0}+a_{1} p H+a_{2} p H^{2}+a_{3} p H^{3}
$$

Kim and Batchelor (2001) used the same polynomial equation to describe the concentration of $\mathrm{Cr}$ and $\mathrm{Cu}$ as a function of $\mathrm{pH}$. However, the authors used a different empirical equation for $\mathrm{Cd}, \mathrm{Pb}$, and $\mathrm{Zn}$ :

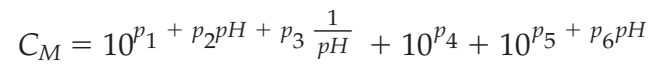

where $C_{M}$ is the equilibrium concentration of metal; this model has six fitting coefficients to be determined by regression. This equation was earlier used by Côté (1986) to describe the solubility behavior of chromium and cadmium hydroxides in a fly ash system.

The aim of this work is to model the equilibrium concentration of $\mathrm{Zn}, \mathrm{Pb}$, and $\mathrm{Cr}$ from untreated and $\mathrm{S} / \mathrm{S}$ steel foundry dust using experimental data obtained from the ANC test. The results obtained from the geochemical mechanistic model Visual MINTEQ and from an empirical model developed by the authors for amphoteric metals are presented.

\section{Experimental Methods}

\section{Experimental procedures}

Two EAFD samples $\left(\mathrm{EAFD}_{1}\right.$ and $\mathrm{EAFD}_{2}$ ) were received from a local steelmaking plant and characterized by acid digestion (based on APHA $3030 \mathrm{H}$ using $\mathrm{HNO}_{3}$ and $\mathrm{HClO}_{4}$ ), $\mathrm{XRF}$ and $\mathrm{XRD}$; the oxide and metal composition of $\mathrm{EAFD}_{1}$ and $\mathrm{EAFD}_{2}$ samples has been previously reported in Fernández-Olmo et al. (2007).

Three cement/EAFD formulations ranging from 7 to $20 \%$ dry wt of cement were prepared (M0: $7 \mathrm{wt} \%$; M3: $11 \mathrm{wt} \%$; M6: $20 \mathrm{wt} \%$ ). The cement type was Portland cement CEM I $42.5 \mathrm{R}$ according to EN-UNE 80301-96. The mixing was performed according to ASTM C305 mixing procedure for cement pastes at a water to total solids ratio of 0.30 . The paste was poured into plastic moulds for curing at room temperature for 28 and 56 days.

The Acid Neutralization Capacity Test (ANC) (Stegemann and Côté, 1990) of untreated and stabilized EAFD was performed to determine the leaching behavior of $\mathrm{Zn}, \mathrm{Pb}$, and $\mathrm{Cr}$ as a function of $\mathrm{pH}$. ANC is a multiple step single-extraction batch leaching test; 11 series of ground (less than $125 \mu \mathrm{m}$ ) and dried samples were mixed with a nitric acid solution of increasing acidity for 24 hours at a liquid to solid ratio of 6 . 
The leachate $\mathrm{pH}$ was measured and the concentration of heavy metals was determined by inductively coupled plasma emission spectroscopy (ICP-ES).

\section{Equilibrium models}

The geochemical model Visual MINTEQ v. 2.32 was used to describe the solubility of $\mathrm{Zn}, \mathrm{Pb}$, and $\mathrm{Cr}$ as a function of pH (Gustafsson, 2005). Visual MINTEQ is a Windows version of MINTEQ A2, which was released by the U.S. EPA in 1999. It is a chemical equilibrium model for the calculation of metal speciation and solubility equilibria for natural waters and soils. The latest versions of Visual MINTEQ allow the use of a liquid to solid ratio parameter in order to represent the leaching of a solid form. Different solid phases can be selected from the original database developed for MINTEQ A2 and the concentration of metal species in aqueous solutions is calculated depending on the $\mathrm{pH}$ and ionic strength of the leaching media. However, the thermodynamic database of Visual MINTEQ does not include formation constants of cement hydrates; so the main limitation of this software is the modeling of metal solubility from cement-stabilized/solidified wastes.

Considering the amphoteric behavior of $\mathrm{Zn}, \mathrm{Pb}$, and $\mathrm{Cr}$ in untreated and treated EAFD, an empirical model based on the dissolution of these metals in the acidic zone and the re-dissolution of hydroxides in the alkaline zone has been considered. The model was based on the theoretical solubility behavior of metal hydroxides, which is governed by the equilibrium:

$$
\mathrm{M}(\mathrm{OH})_{z}(\mathrm{~s}) \Leftrightarrow \mathrm{M}^{\mathrm{z}}+\mathrm{zOH} \mathrm{H}^{-}
$$

In the acidic region, the solubility of metal is calculated by the equation (6):

$$
\left[M^{z+}\right]=\frac{K_{s}}{\left[O H^{-}\right]^{z}}=\frac{K_{s}}{K_{w} z}\left[H^{+}\right]^{z}=K^{\prime}\left[H^{+}\right]^{z}
$$

where $K_{s}$ is the solubility product constant of metal hydroxide, $K_{w}$ the water ionization constant, and $\mathrm{K}^{\prime}$ a lumped constant for the acidic region.

Metal cations may form different complexes with $\mathrm{OH}^{-}$according to the following equation:

$$
\mathrm{M}^{z+}+j \mathrm{OH}^{-} \Leftrightarrow \mathrm{M}(\mathrm{OH})_{j}^{z-j}
$$

The concentration of any metal complex is calculated by the equation (8):

$$
\begin{aligned}
& {\left[\mathrm{M}(\mathrm{OH})_{j}^{z-j}\right]=\beta_{j}\left[\mathrm{M}^{z+}\right]\left[O H^{-}\right]^{j}} \\
& \quad=\beta_{j} K_{s} K_{w}{ }^{j-z} \frac{1}{\left[H^{+}\right]^{j-z}}=K_{j}^{\prime \prime} \frac{1}{\left[H^{+}\right]^{j-z}}
\end{aligned}
$$

where $\beta_{\mathrm{j}}$ is the equilibrium constant of equation (7) and $K_{j}^{\prime \prime}$ is a lumped constant for each metal complex. The metal solubility is calculated by the sum of all the metal species:

$$
C_{M}=\left[M^{z+}\right]+\sum_{j=1}^{n}\left[M(O H)_{j}^{z-j}\right]
$$

This model can be simplified assuming that $M^{z+}$ and $M(O H) j_{1}{ }^{z-j_{1}}\left(\mathrm{j}_{1}>\mathrm{z}\right)$ are the main metal species dissolved in the acidic and alkaline region respectively, the metal solubility will be given by equation (10):

$$
C_{M}=K^{\prime}\left[H^{+}\right]^{z}+K_{j 1}^{\prime \prime} \frac{1}{\left[\mathrm{H}^{+}\right]^{j_{1}-z}}
$$

The following empirical equation is proposed to describe the metal solubility in the acidic region:

$$
C_{M}=C_{o}\left[\frac{1}{\left(1+k_{1} \frac{1}{\left[H^{+}\right]}\right)^{n_{1}}}\right]
$$

where $C_{o}$ is the concentration of metal available for leaching; $\mathrm{k}_{1}$ and $\mathrm{n}_{1}$ are empirical parameters.

$$
\begin{gathered}
\text { When } 1<<k_{1} \frac{1}{\left[H^{+}\right]^{\prime}} \text {, equation (11) becomes } \\
\qquad C_{M}=\frac{C_{o}}{k_{1}^{n_{1}}}\left[H^{+}\right]^{n_{1}}=K_{e}^{\prime}\left[H^{+}\right]^{n_{1}}
\end{gathered}
$$

which is similar to equation (6); $K_{e}^{\prime}$ is a lumped empirical parameter and $n_{1}$ represents the slope of the concentration vs $\mathrm{pH}$ plot in logarithmic scale.

The proposed empirical equation for the alkaline region is:

$$
C_{M}=C_{o}\left[\frac{1}{\left.\left(1+k_{2} H^{+}\right]\right)^{n 2}}\right]
$$

where $\mathrm{k}_{2}$ and $\mathrm{n}_{2}$ are empirical parameters. When $1<<$ $k_{2}\left[H^{+}\right]$, equation (13) becomes

$$
C_{M}=\frac{C_{o}}{k_{2}^{n 2}} \frac{1}{\left[H^{+}\right]^{n 2}}=\frac{K_{e}}{\left[H^{+}\right]^{n 2}}
$$

which is similar to equation (8); $K_{e}$ is a lumped empirical parameter and $n_{2}$ represents the slope of the concentration vs $\mathrm{pH}$ plot in logarithmic scale in the alkaline region.

Thus, the solubility of metals in the whole $\mathrm{pH}$ range is then calculated by summing equations (11) and (13) leading to the empirical model shown in equation (15):

$$
C_{M}=C_{o}\left[\frac{1}{\left(1+k_{1} \frac{1}{\left[H^{+}\right]}\right)^{n_{1}}}+\frac{1}{\left(1+k_{2}\left[H^{+}\right]\right)^{n_{2}}}\right]
$$

The model has four parameters, $\mathrm{k}_{1}$ and $\mathrm{n}_{1}$ for the acidic region and $k_{2}$ and $n_{2}$ for the alkaline region. These parameters were obtained after minimization of the relative standard deviation (equation 16) between experimental and simulated data using an optimization software.

$$
\sigma=\sqrt{\frac{\sum\left(\frac{\mathcal{c}_{\exp }-c_{\text {sim }}}{c_{\exp }}\right)^{2}}{n-1}}
$$

\section{Results and Discussion}

\section{Characterization of EAFD}

The XRF analysis of EAFD 1 and EAFD 2 samples allows to identify zinc and iron oxides as the main components (40.2-48.2\% dry wt $\mathrm{ZnO}$ and $29.9-36.0 \%$ dry wt $\mathrm{Fe}_{2} \mathrm{O}_{3}$ ), while calcium and magnesium oxides were minor components, leading to an alkaline $\mathrm{pH}$ in water. Other pollutants were found at lower levels, being $\mathrm{Pb}, \mathrm{Cr}, \mathrm{Cu}$, and $\mathrm{Cd}$ the most important contaminants from the environmental point of view. The XRD analysis revealed that zinc ferrite $\left(\mathrm{ZnFe}_{2} \mathrm{O}_{4}\right)$ and zincite $(\mathrm{ZnO})$ were the main crystalline phases; this means that iron is present mainly in trivalent oxidation state. These results agree with that found in the literature (Sofilic et al., 2004), except for the case of iron, which is usually found as 
magnetite $\left(\mathrm{Fe}_{3} \mathrm{O}_{4}\right)$ (Stegemann et al, 2000; Machado et al., 2006).

\section{Leaching of zinc, lead, and chromium}

The concentration of zinc, lead and chromium measured in the leachate of ANC test is shown against leachate $\mathrm{pH}$ in Figures 1-3 respectively for untreated and treated EAFD samples. Each point shown in Figures 1-3 has been determined at equilibrium conditions. An amphoteric behavior is observed for three metals. The minimum of the solubility curve is found between $\mathrm{pH} 8$ to 10 for zinc and lead and between 6 to 10 for chromium. Similar zinc and lead solubility curves were obtained from synthetic metal oxides $\left(\mathrm{ZnO}, \mathrm{Fe}_{2} \mathrm{O}_{3}, \mathrm{PbO}\right.$, $\mathrm{Cr}_{2} \mathrm{O}_{3}$ )/Portland cement formulations; however, chromium (III) showed an acidic behavior (Fernández-Olmo et al., 2003). The leaching of lead from untreated EAFD in the neutral to alkaline regions is slightly higher than that of cement-stabilized EAFD, probably due to some adsorption of lead onto hydrated calcium silicate (Moulin et al., 1999). Figure 1 shows that below pH 5.5 most of zinc available for leaching is released. The availability of zinc in untreated EAFD calculated from the maximum release under strongly acidic conditions is $79 \%$ and $85 \%$ of the total zinc content for $\mathrm{EAFD}_{1}$ and $\mathrm{EAFD}_{2}$ respectively. The unleached fraction is probably due to the zinc ferrite content, which is practically insoluble in this $\mathrm{pH}$ range (Huber et al., 2001). Contrary to the zinc solubility behavior, a flat region is not clearly observed for lead in the acidic region; however, an unleached fraction of approximately $40 \%$ is still remaining at the lowest $\mathrm{pH}$. With respect to chromium, the low concentration and the amphoteric behavior found indicate that mainly trivalent chromium is contained in the studied EAFD samples. It is well known that hexavalent chromium is soluble in the studied range of $\mathrm{pH}$. The maximum amount of dissolved chromium in the acidic region was below $7 \%$ of total chromium.
Visual MINTEQ (v. 2.31) was used in our previous work to simulate the solubility of $\mathrm{Zn}$ with $\mathrm{pH}$ in untreated EAFD (Fernández-Olmo et al., 2007). Zincite (ZnO) and amorphous and crystalline $\mathrm{Zn}(\mathrm{OH})_{2}$ solubility data were contained in the database; however, zinc ferrite was not included in the database; thus, zincite and $\mathrm{Zn}(\mathrm{OH})_{2}$ were considered as the main Zn solid species.

Two simulation models based on Visual MINTEQ were used to describe the zinc solubility curves of untreated EAFD (Fernández-Olmo et al., 2007).

a. Considering zincite $(\mathrm{ZnO})$ as the only compound present in the solid phase. The amount of $\mathrm{ZnO}$ corresponding to the experimental availability of zinc in EAFD was introduced in $\mathrm{mol} / \mathrm{kg}$.

b. Considering the major oxides in the solid phase: zincite $(\mathrm{ZnO})$, lime $(\mathrm{CaO})$ and periclase $(\mathrm{MgO})$; since zinc ferrite $\left(\mathrm{ZnO} \cdot \mathrm{Fe}_{2} \mathrm{O}_{3}\right)$ was not considered in the database, hematite $\left(\mathrm{Fe}_{2} \mathrm{O}_{3}\right)$ was also included to account for the iron content of EAFD.

Simulation (b) showed a lower standard deviation according to equation (16) for untreated EAFD (FernándezOlmo et al., 2007). Taking into account that zinc solubility curves obtained from stabilized EAFD are similar to that obtained from untreated EAFD (Fig. 1), model (b) was also used to describe the experimental curves for the stabilized EAFD samples cured for 28 and 56 days (Fig. 4). Obviously, it is a simplified model since cement hydration thermodynamic data are not considered in Visual MINTEQ database. Figure 4 also shows that curing time does not affect the leaching behavior of zinc in stabilized EAFD samples.

The use of zincite as solid phase in stabilized EAFD in Visual MINTEQ simulations describes well the solubility of

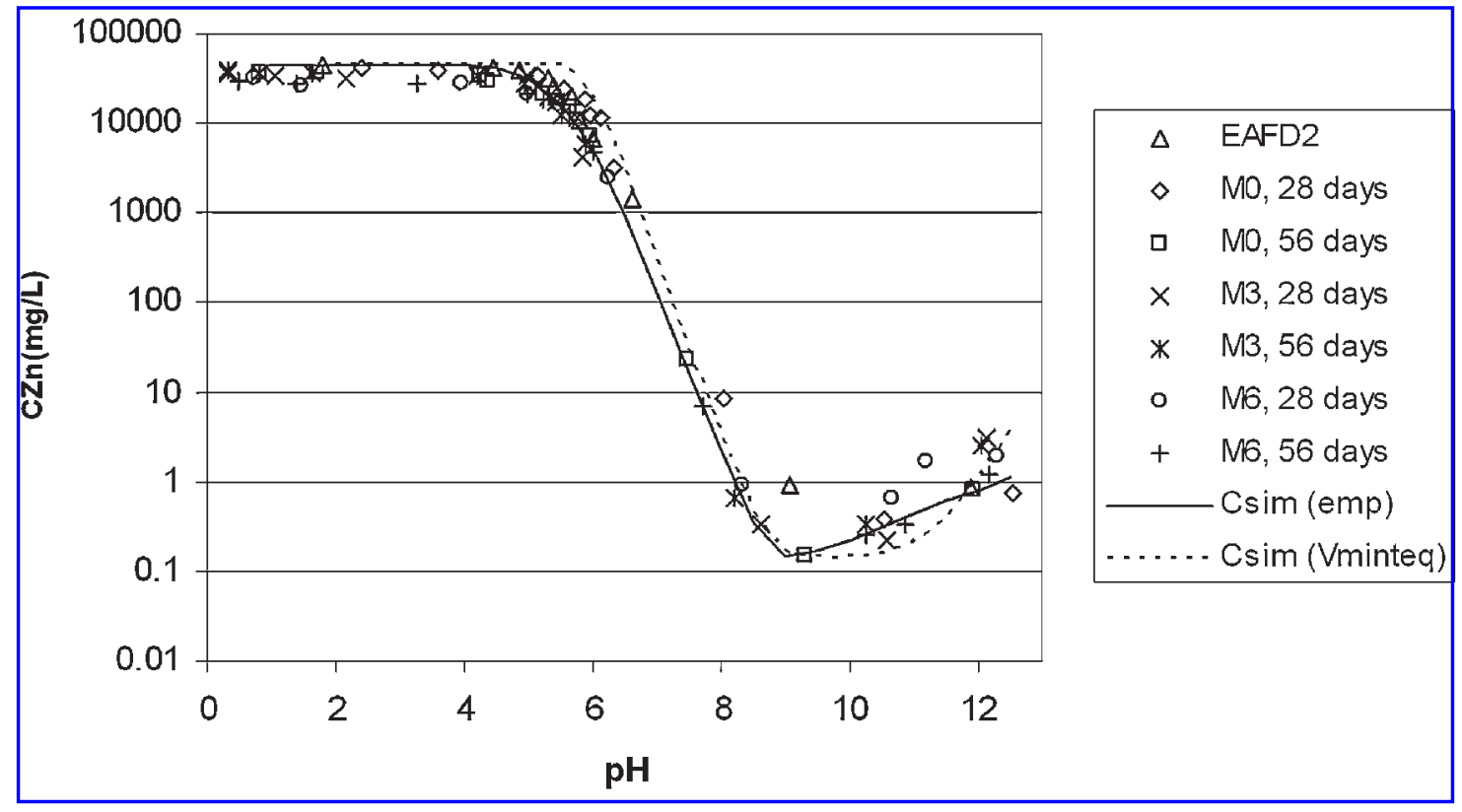

FIG. 1. Solubility of zinc as a function of leachate $\mathrm{pH}$ for untreated and treated EAFD waste: experimental vs. simulated curves (using Visual MINTEQ v. 2.32 and the empirical model shown in equation 15). *Experimental data from FernándezOlmo et al. (2007). 


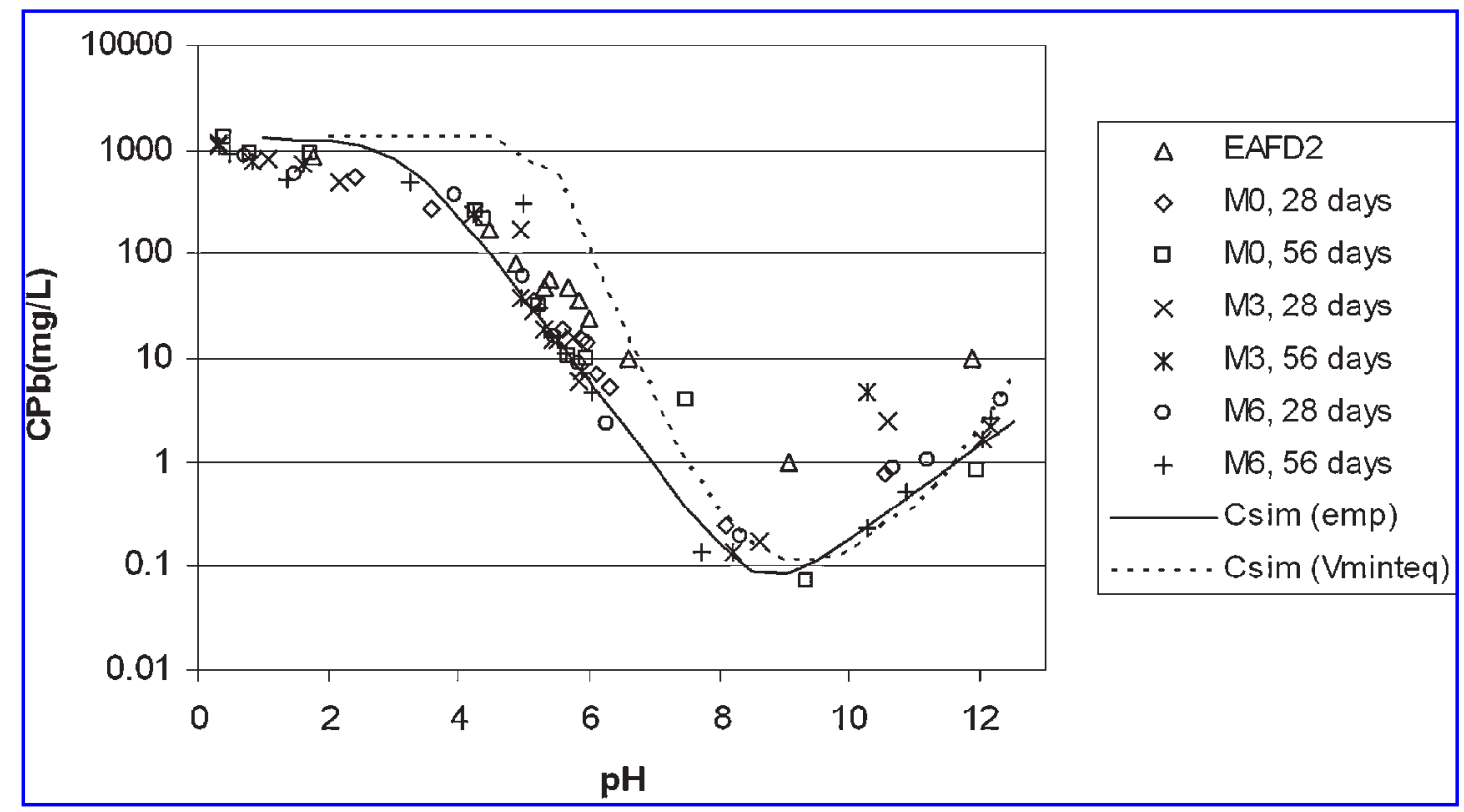

FIG. 2. Solubility of lead as a function of leachate $\mathrm{pH}$ for untreated and treated EAFD waste: experimental vs. simulated curves (using Visual MINTEQ v. 2.32 and the empirical model shown in equation 15).

zinc; however, metal oxides contained in wastes derived from thermal processes are usually present in hydroxide forms after the hydration reactions which take place in stabilization/solidification processes. The theoretical solubility of amorphous $\mathrm{Zn}(\mathrm{OH})_{2}$ has been calculated with Visual MINTEQ and it is shown in Figure 5 with zincite $(\mathrm{ZnO})$; it can be observed that $\mathrm{Zn}(\mathrm{OH})_{2}$ is more soluble than zincite, leading to a higher simulation error. The Visual MINTEQ code allows to describe the behavior of zinc leaching from stabilized EAFD by using the option "Oversaturated solids are allowed to precipitate each time a mineral precipitates or dissolves", even if $\mathrm{Zn}(\mathrm{OH})_{2}$ is considered as the main zinc solid phase. When this option is used, the metal solubility is governed by the less soluble solid phase (i.e. zincite instead of $\left.\mathrm{Zn}(\mathrm{OH})_{2}\right)$.

With respect to lead, the Visual MINTEQ database contains solubility data of some lead oxides and hydroxides: Litharge $(\mathrm{PbO})$, Massicot $(\mathrm{PbO}), \mathrm{Pb}_{2} \mathrm{O}(\mathrm{OH})_{2}, \mathrm{PbO}^{\circ} 0.3 \mathrm{H}_{2} \mathrm{O}$, and $\mathrm{Pb}(\mathrm{OH})_{2}$. The solubility of these compounds has been plotted in Figure 6 together with the experimental curve of lead leached from EAFD 2 sample. Although the amphoteric behavior of lead in EAFD matrices is described qualitatively, none of these models fit quantitatively the experimental results. When the option "Oversaturated solids are allowed to precipitate each time a mineral precipitates or dissolves" is used, lead solubility is governed by the less

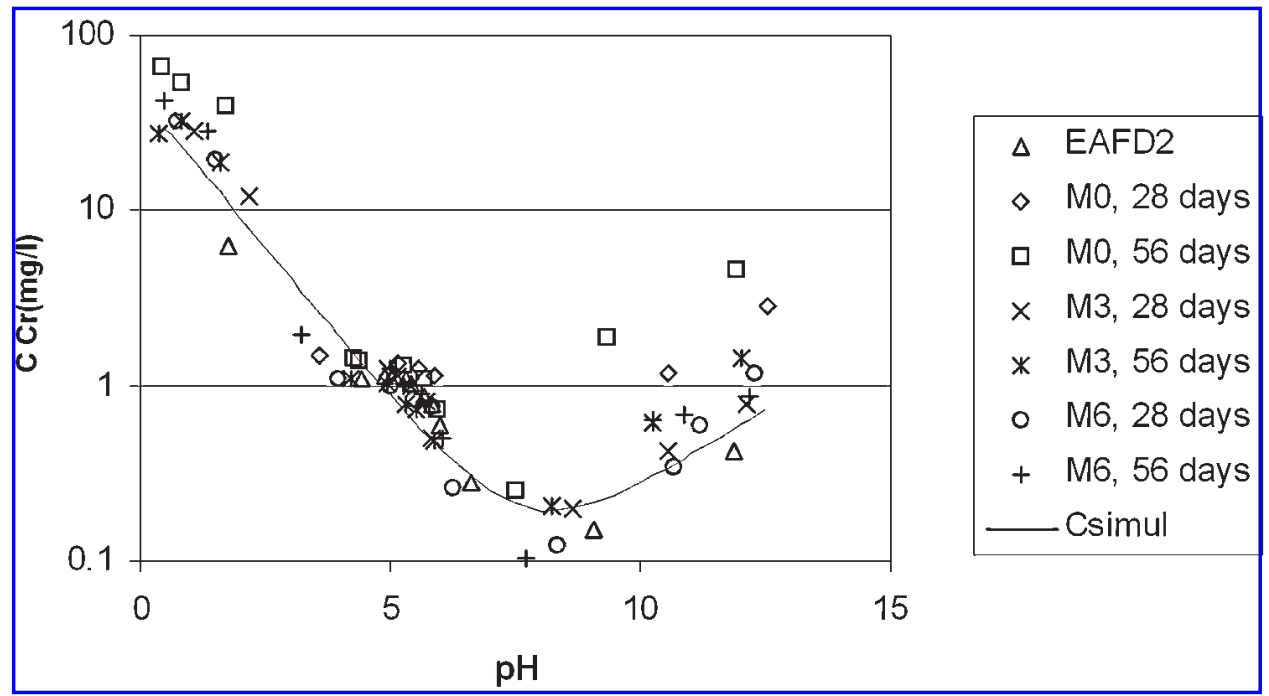

FIG. 3. Solubility of chromium as a function of leachate $\mathrm{pH}$ for untreated and treated EAFD waste: experimental vs. simulated curves (using the empirical model shown in equation 15). 

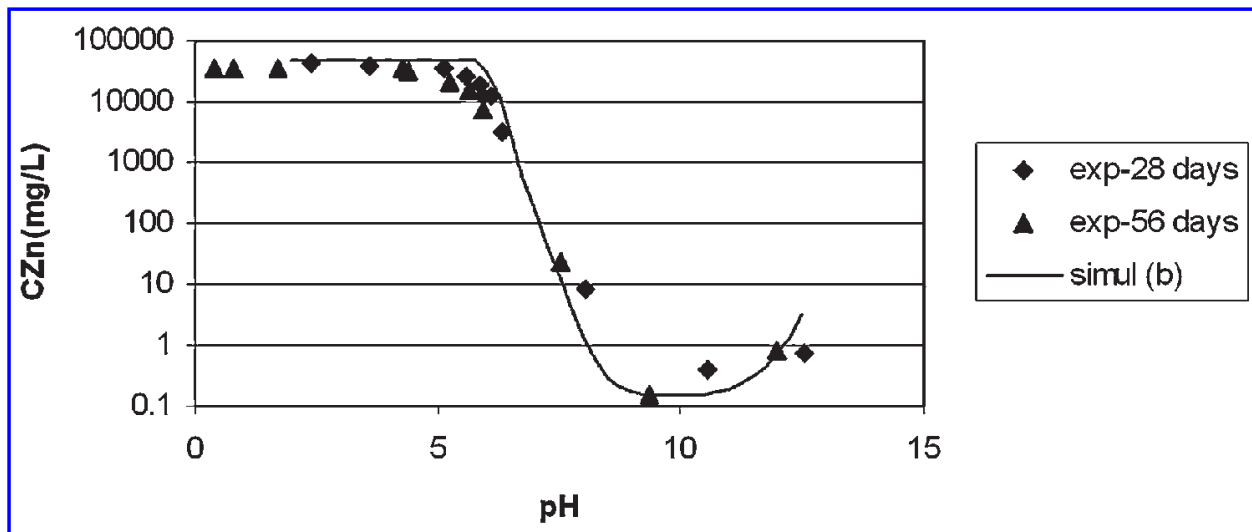

(a)
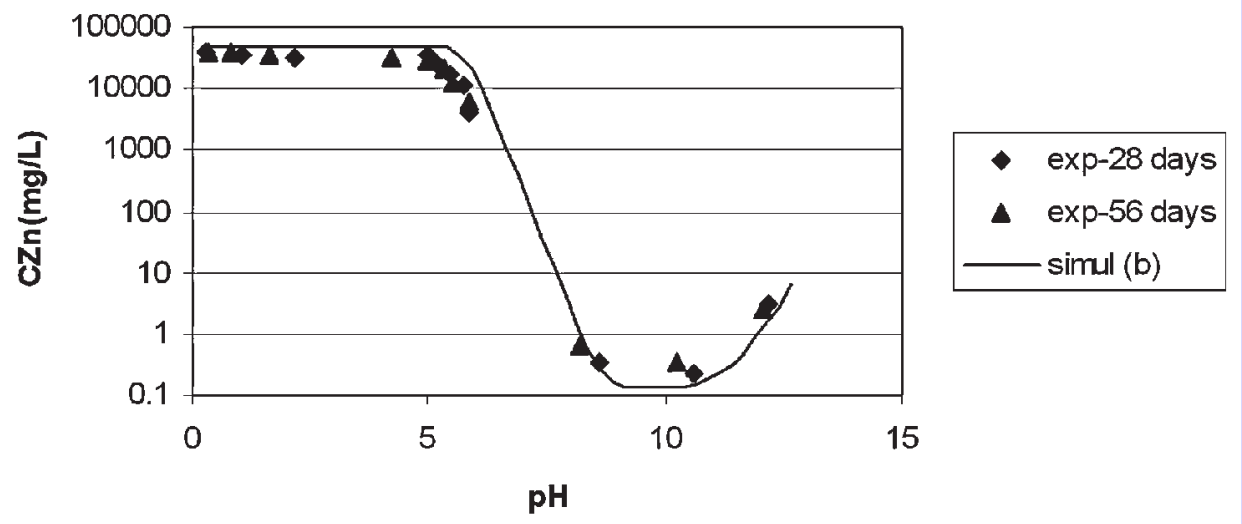

(b)

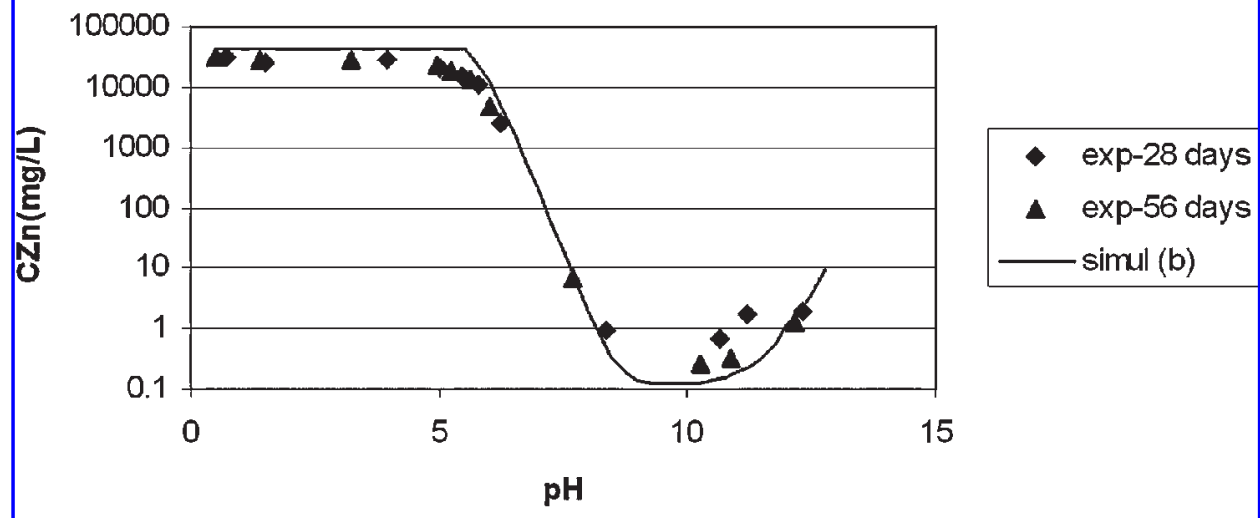

(c)

FIG. 4. Solubility of zinc as a function of leachate $\mathrm{pH}$ for S/S EAFD: experimental vs. simulated curves (using Visual MINTEQ v. 2.32): (a) M0; (b) M3; (c) M6. *Experimental data from Fernández-Olmo et al. (2007).

soluble solid phase (i.e. $\left.\mathrm{Pb}(\mathrm{OH})_{2}\right)$. However, the theoretical solubility of $\mathrm{Pb}(\mathrm{OH})_{2}$ in the neutral $\mathrm{pH}$ range is several orders of magnitude lower than the experimental values. De Windt and Badreddine (2007) performed a fitting procedure to ANC data obtained from a synthetic solidified waste prepared from $\mathrm{PbCl}_{2}$ in order to recalculate the formation constant of $\mathrm{Pb}(\mathrm{OH})_{2}$ according to equation (17).

$$
\mathrm{Pb}^{2+}+2 \mathrm{H}_{2} \mathrm{O} \rightarrow \mathrm{Pb}(\mathrm{OH})_{2}+2 \mathrm{H}^{+}
$$

The log K obtained from the Visual MINTEQ database (v. 2.32) is -8.15 while the fitted $\log K$ reported by De Windt 


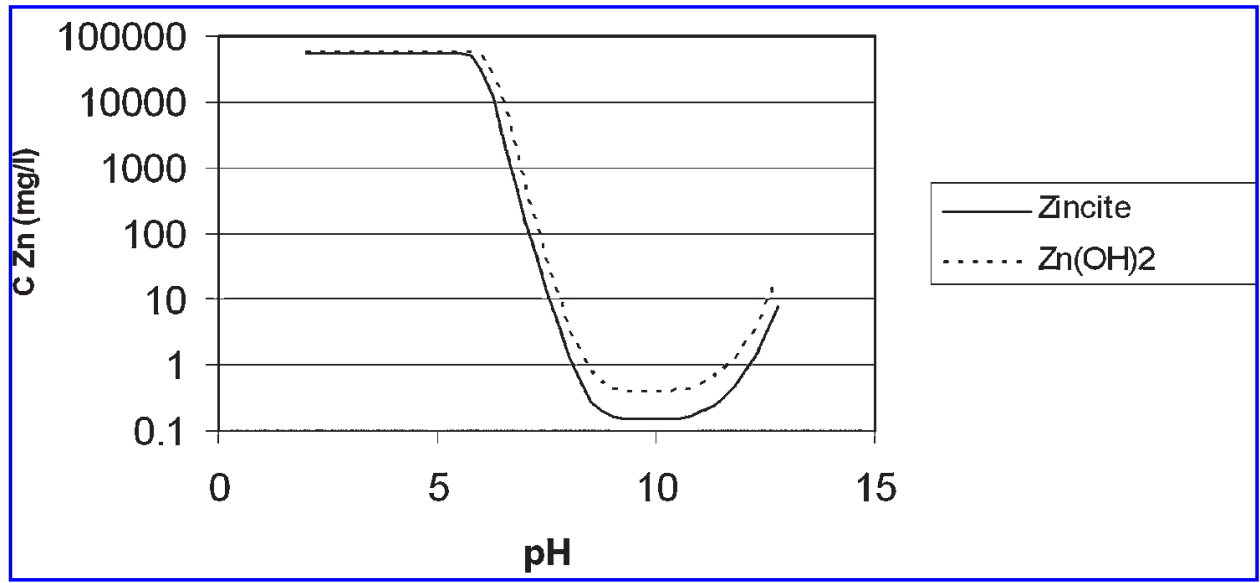

FIG. 5. Theoretical solubility curves of zincite $(\mathrm{ZnO})$ and amorphous $\mathrm{Zn}(\mathrm{OH})_{2}$ calculated by Visual MINTEQ v. 2.32.

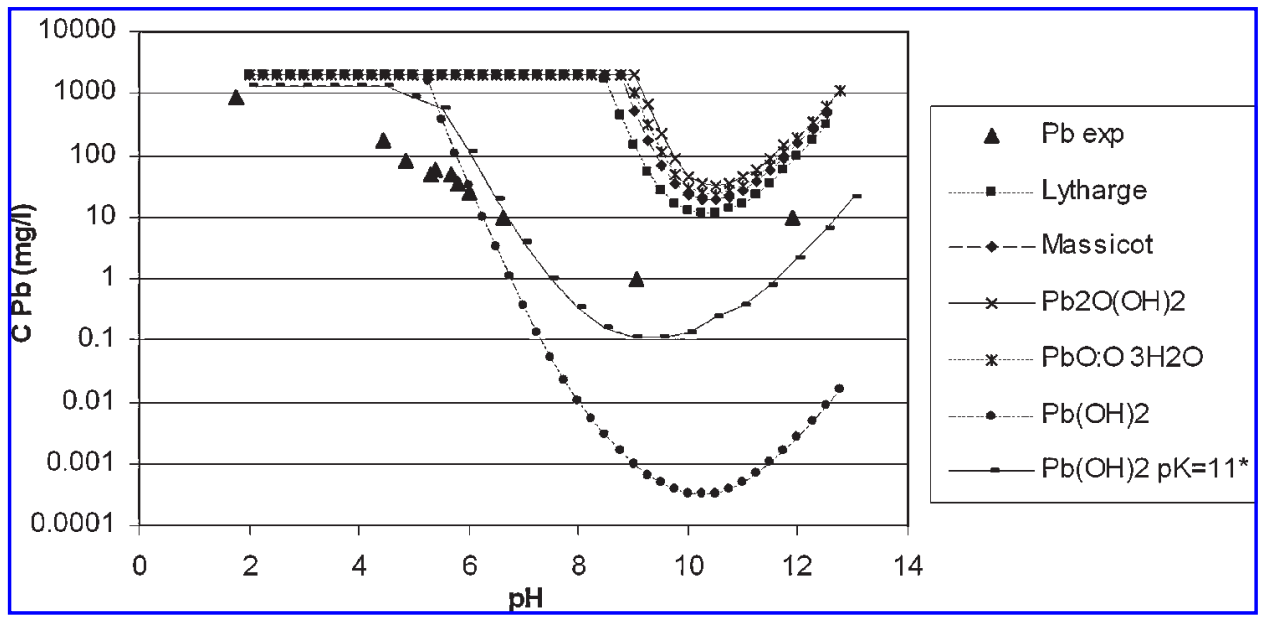

FIG. 6. Solubility of lead as a function of leachate $\mathrm{pH}$ for untreated EAFD waste: experimental vs. simulated curves (using Visual MINTEQ v. 2.32). *The formation constant of $\mathrm{Pb}(\mathrm{OH})_{2}$ was modified according to De Windt and Badreddine (2007).

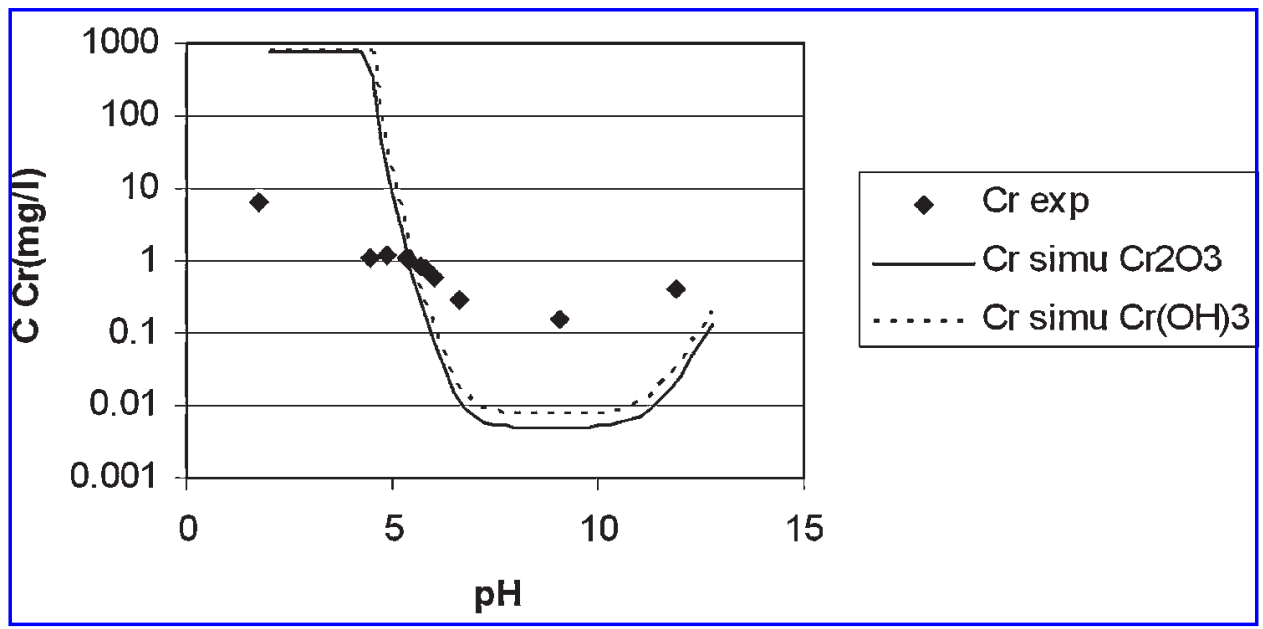

FIG. 7. Solubility of chromium as a function of leachate $\mathrm{pH}$ for untreated EAFD waste: experimental vs. simulated curves (using Visual MINTEQ v. 2.32). 


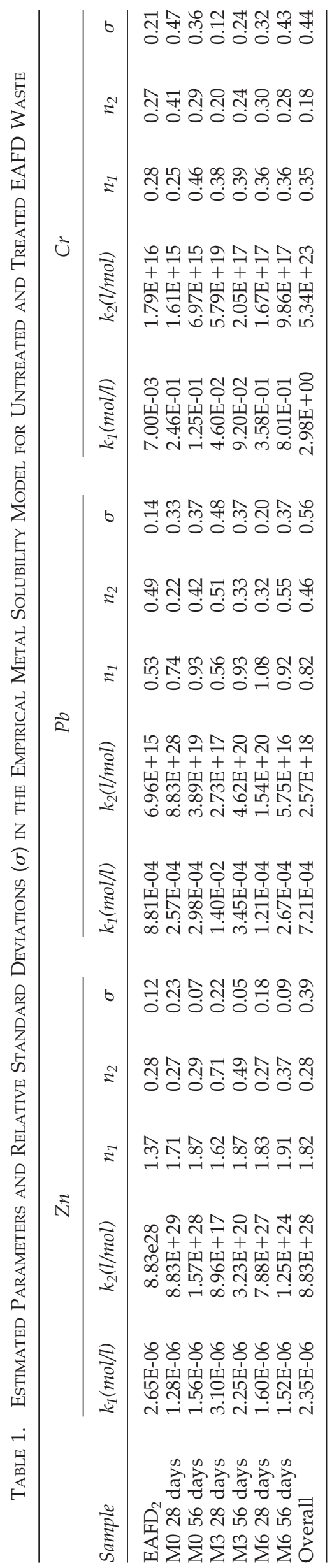


and Badreddine (2007) is -11. A new simulation was performed considering the following assumptions:

- taking into account that only $60 \%$ of lead was leached out at the lowest $\mathrm{pH}$ value, the unleached fraction of lead was attributed to anglesite $\left(\mathrm{PbSO}_{4}\right)$, which is almost insoluble in this $\mathrm{pH}$ region;

- lead sulfate and chloride were also included in the simulation together with litharge $(\mathrm{PbO})$; the leaching of lead in the acidic to neutral region may be influenced by the chloride content, probably due to blixite $\left(\mathrm{Pb}_{2}(\mathrm{OH})_{3} \mathrm{Cl}\right)$ (De Windt and Badreddine, 2007);

- the minimum of the solubility curve and the alkaline zone were governed by the $\mathrm{Pb}(\mathrm{OH})_{2}$ phase; according to previous results reported by De Windt and Badreddine (2007) a modified formation constant of $\mathrm{Pb}(\mathrm{OH})_{2}(\log \mathrm{K}=-11)$ was used;

- the adsorption of lead onto hydrated calcium silicate in stabilized EAFD is neglected.

This simulation is plotted in Figure 2 showing a better description of the solubility curve.

The trivalent chromium solid phases available in the Visual MINTEQ database are $\mathrm{Cr}_{2} \mathrm{O}_{3}$ and $\mathrm{Cr}(\mathrm{OH})_{3}$. The solubility of these compounds has been plotted in Figure 7 together with the experimental curve of chromium leached from $\mathrm{EAFD}_{2}$ sample. It can be observed from Figure 7 that the leaching of chromium from EAFD matrices is not well described by the geochemical model, probably because the chromium solid phases controlling the release of chromium from these matrices are not included in the database.

The empirical model shown in equation (15) was used to fit the experimental solubility curves of zinc, lead, and chromium in untreated and treated EAFD. The four parameters of the model were estimated for untreated and stabilized EAFD after 28 and 56 days of curing and they are shown in Table 1 . In addition, taking into account the similarity of experimental curves obtained for each metal, the experimental data of each metal were considered together for the estimation of the parameters of the model. The values of these parameters are also shown in Table 1 and the curves obtained from the empirical model for zinc, lead, and chromium using these parameters are plotted in Figures 1-3 respectively, together with the experimental data for untreated and stabilized EAFD waste. The metal solubility curves obtained from Visual MINTEQ v. 2.32 were also plotted in Figures 1-3 in order to compare both models.

In the case of zinc, the best simulation performed with $\mathrm{Vi}$ sual MINTEQ (simulation b) is plotted in Figure 1. It can be observed that both models describe well the experimental solubility of zinc. Figure 2 shows that the empirical model for lead solubility is slightly better as compared to the best simulation performed by Visual MINTEQ using the assumptions reported above, mainly in the acidic region. The slope of lead concentration-pH plot in semi-log scale for blixite $\left(\mathrm{Pb}_{2}(\mathrm{OH})_{3} \mathrm{Cl}\right)$ is about $3 / 2$, while the value of the empirical parameter in the acidic region $\left(n_{1}\right)$ is 0.816 , which explains the discrepancies found between both models in this $\mathrm{pH}$ range. With respect to chromium, the empirical model fits well the chromium leaching data in the whole $\mathrm{pH}$ range (Fig. 3), meanwhile Visual MINTEQ does not allow a quantitative description of these data.

\section{Acid neutralization capacity}

The Acid Neutralization Capacity (ANC) of untreated EAFD is shown in Figure 8. The Visual Minteq software allows to simulate the resulting $\mathrm{pH}$ of a specified mix of solid phases after leaching at a given liquid to solid ratio; thus, the simulation of the ANC curve of EAFD was performed using as major solid phases zincite $(\mathrm{ZnO})$, hematite $\left(\mathrm{Fe}_{2} \mathrm{O}_{3}\right)$, lime $(\mathrm{CaO})$ and periclase $(\mathrm{MgO})$, and different amounts of 2 $\mathrm{N}$ nitric acid in water as leachant. The experimental ANC curve is not well described quantitatively, but the qualitative behavior is similar, as can be observed in Figure 8. Three different plateaus are found in the simulated curve corresponding to lime, periclase and zincite, at $\mathrm{pH} 12,9$, and 6 respectively; about 6-7 equivalents of acid per kilogram of EAFD are required to neutralize all the zinc oxide. This explains that most of the experimental data of zinc, lead and chromium concentration are found at $\mathrm{pH} 5.5-6$ (Figs. 1, 2, and 3); after this point, $\mathrm{pH}$ drops sharply. The plateaus of

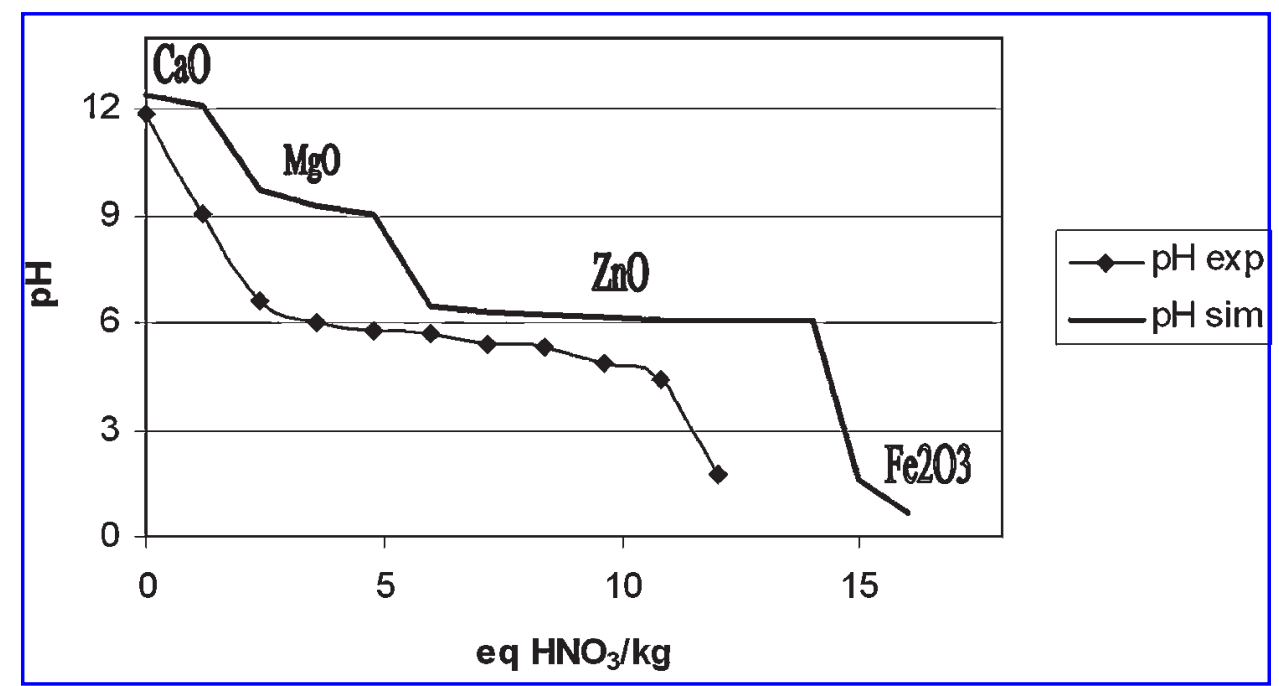

FIG. 8. ANC curve of untreated EAFD: the simulated curve was calculated by Visual MINTEQ v. 2.32. 
lime and periclase are not observed in the experimental curve.

\section{Conclusions}

The modeling of solubility data of the amphoteric heavy metals, zinc, lead, and chromium contained in untreated and stabilized EAFD samples is presented. Solubility data were obtained from an ANC test, which is a pH-dependence leaching test. The characterization of EAFD samples revealed that zincite and zinc ferrite were the main solid phases. Zinc was the major contaminant of EAFD, while lead and chromium were also detected at lower concentrations. The studied metals show an amphoteric behavior in the ANC test. To describe this behavior a mechanistic geochemical model, Visual MINTEQ was first used. In addition, an empirical model was developed and used to fit the solubility data of three metals. Both simulation models describe well the solubility of zinc in EAFD matrices. The unleached fraction of zinc was thought to be due to zinc ferrite phase. With respect to lead, $\mathrm{Pb}(\mathrm{OH})_{2}$ solubility constant had to be modified $(\log \mathrm{K}=$ -11) when Visual MINTEQ was used in order to describe the leaching of lead mainly in the neutral to alkaline region. The unleached lead fraction was probably due to anglesite, while the chloride present in EAFD could affect the solubility of lead in the acidic region. The empirical model provides a better fitting of data, mainly in the acidic region. Visual MINTEQ fails to describe quantitatively the solubility data of chromium, meanwhile the empirical model does work well in the whole $\mathrm{pH}$ range. Finally, Visual MINTEQ was also used to describe the ANC data of untreated EAFD; the main plateau corresponding to zincite was well described, but the minor plateaus predicted by Visual MINTEQ (MgO and $\mathrm{CaO}$ ) were not observed in the experimental curve.

In summary, the empirical model shows some advantages with respect to the geochemical model: first, the users of geochemical models must know the composition of metal solid phases in order to perform the calculations, but metal speciation in waste-derived forms is usually not well understood. In addition, the experimental solubility data are not always properly described by geochemical models; in such situations, the empirical model seems to be more appropriate. Furthermore, geochemical models generate series of metal concentration- $\mathrm{pH}$ data which cannot be introduced into dynamic leaching models; solubility-pH mathematical equations, such as that provided by an empirical model, are required for dynamic models.

\section{Acknowledgments}

This work has been developed within the framework of CTM2006-0317/TECNO project funded by the Spanish MEC.

\section{Author Disclosure Statement}

No competing interests exist.

\section{Nomenclature}

$\mathrm{a}_{\mathrm{i}} \quad=$ coefficients of the polynomial equation (3)

$\mathrm{C}_{\exp }=$ experimental metal concentration in ANC leachates

$\mathrm{C}_{\mathrm{im}}=$ metal concentration of solid species

$\mathrm{C}_{\mathrm{M}}=$ metal concentration at equilibrium conditions
$\mathrm{C}_{\mathrm{mo}}=$ metal concentration of mobile species

$\mathrm{C}_{\mathrm{o}}=$ metal concentration available for leaching

$\mathrm{C}_{\text {sim }}=$ simulated metal concentration

$\mathrm{k}=$ dissolution rate constant

$\mathrm{k}_{1}=$ empirical parameter for the acidic region in equations (11) and (15)

$\mathrm{k}_{2}=$ empirical parameter for the alkaline region in equations (13) and (15)

$\mathrm{K}_{\mathrm{d}} \quad=$ equilibrium constant defined in equation (1)

$\mathrm{K}_{\mathrm{s}} \quad=$ solubility product constant

$\mathrm{K}_{\mathrm{w}} \quad$ = water ionization constant

$K^{\prime}=$ lumped constant for the acidic region

$K_{e}^{\prime} \quad=$ lumped parameter in equation (12)

$K_{j}^{\prime \prime} \quad=$ lumped constant for the alkaline region

$K_{e}^{\prime \prime} \quad=$ lumped parameter in equation (14)

$\mathrm{n}_{1}=$ empirical slope for the acidic region in equations (11) and (15)

$\mathrm{n}_{2} \quad=$ empirical slope for the alkaline region in equations (13) and (15)

$\mathrm{p}_{\mathrm{i}} \quad=$ empirical parameters in equation (4)

$\mathrm{v} \quad=$ dissolution rate of contaminant

\section{Greek symbols}

$\beta_{\mathrm{j}}=$ equilibrium constant of equation (7)

$\sigma=$ standard deviation

\section{References}

Andres, A. and Irabien, J.A. (1994a). The influence of binder/ waste ratio on leaching characteristics of solidified/stabilized steel foundry dust. Environ. Technol. 15, 343.

Andres, A. and Irabien, J.A. (1994b). Study of solidification/ stabilization process of steel foundry dust using cement based binders: influence of the processing variables. Waste Manage. Res. 12, 405.

Andrés, A., Ortiz, I, Viguri, J., and Irabien, J.A. (1995) Long-term behaviour of toxic metals in stabilized steel foundry dusts. $L$. Hazard. Mater. 40, 31.

Catalan Lionel J.J, Merliere E., and Chezick C. (2002). Study of the physical and chemical mechanisms influencing the longterm environmental stability of natrajarosite waste treated by stabilization/solidification. J. Hazard. Mater. B94, 63.

Côté, P.L. (1986). Contaminant Leaching from Cement-Based Waste Forms under Acidic Conditions, Ph.D. Thesis, McMaster University, Hamilton, Ont.

Côté, P.L., Constable, T.W., and Moreira, A. (1987). An evaluation of cement-based waste forms using the results of approximately two years of dynamic leaching. $\mathrm{Nucl}$. Chem. Waste Manag. 7, 129.

Coz, A., Andrés, A., Soriano, S., and Irabien, A. (2004). Environmental behaviour of stabilised foundry sludge. J. Hazard. Mater. B109, 95.

De Windt, L. and Badreddine, R. (2007). Modelling of Longterm dynamic leaching tests applied to solidified/stabilised waste. Waste Manage. 27, 1638.

Dijkstra J.J., Meeussen J.C.L., and Comans R.N.J. (1999). Leaching of heavy metals from contaminated soils: an experimental and modeling study. Environ. Sci. Technol. 38, 4390.

European Commission, (1999). 1999/31/EC Landfill Directive. L182.

European Commission, (2001). Best Available Techniques Reference Document on the Production of Iron and Steel, December 2001. 
Fernández-Olmo, I., Chacon, E., and Irabien, A. (2003). Leaching behavior of lead, chromium (iii), and zinc in cement/metal oxides systems. J. Environ. Eng. 129, 532.

Fernández-Olmo, I., Lasa, C., and Irabien, A. (2007). Modeling of zinc solubility in stabilized/solidified electric arc furnace dust. L. Hazard. Mater. 144, 720.

Fernández-Pereira, C., Rodríguez-Piñero, M., and Vale, J. (2001). Solidification/stabilization of electric arc furnace dust using coal fly ash. Analysis of the stabilization process. J. Hazard. Mater. B82, 183.

Fuessle, R.W. and Taylor, M.A. (2004). Long-term solidification/stabilization and toxicity characteristic leaching procedure for an electric arc furnace dust, L. Environ. Eng. 130, 492.

Gustafsson, J.P., (2005). Visual MINTEQ ver. 2.32, http://www. lwr.kth.se/English/OurSoftware/vminteq/

Gustafsson, J.P., Pechová, P., and Berggren, D. (2003). Modeling metal binding to soils: the role of natural organic matter. Environ. Sci. Technol. 37, 2767.

Hamilton, I.W. and Sammes, N.M. (1999). Encapsulation of steel foundry dusts in cement mortar. Cem. Concr. Res. 29, 55.

Huber, J.C., Rocabois, P., Faral, M., Birat, J.P., Patisson, F., and Ablitzer, D. (2001). La Formation des poussières dans un réacteur sidérurgique. La Revue de Métallurgie, Avril, 399.

Irabien, A., Fernandez-Olmo, I., Andre s, A., and Sebastia , M. (2002). Prediction of TCLP leachates of electric arc furnace dust/cement products using neural network analysis. Environ. Progress 21, 95.

Kim, I. and Batchelor, B. (2001). Empirical partitioning leach model for solidified/stabilized wastes. I. Environ. Eng. 127, 188.

Laforest, G. and Duchesne, J. (2006). Characterization and leachability of electric arc furnace dust made from remelting of stainless steel. I. Hazard Mater. 135, 156.

Li, X.D., Poon, C.S., Sun, H., Lo, I.M.C. and Kirk, D.W. (2001). Heavy metal speciation and leaching behaviours in cement based solidified/stabilized waste materials. J. Hazard. Mater. A82, 215.
Machado, J.G.M.S., Brehm, F.A., Moraes, C.A.M., Dos Santos, C.A., Vilela, A.C.F., and Da Cunha, J.B.M. (2006). Chemical, physical, structural and morphological characterization of electric arc furnace dust. J. Hazard Mater. B136, 953.

Maisse, E. and Pousin, J. (1997). Diffusion and dissolution/precipitation in an open porous reactive medium. L. Comput. Appl. Math. 82, 279.

Meima, J. and Comans, R. (1997). Geochemical modelling of weathering reactions in municipal solid waste incinerator bottom ash, Environ. Sci. Technol. 31, 1269.

Meima, J. and Comans, R. (1998). Application of surface complexation/precipitaction modelling to contaminant leaching from weathered municipal solid waste incinerator bottom ash. Environ. Sci. Technol. 32, 688.

Moulin, I., Stone, W.E.E., Sanz, J., Bottero, J.Y., Mosnier, F., and Haehnel, C. (1999). Lead and zinc retention during hydration of tri-calcium silicate: a study by sorption isotherms and 29Si nuclear magnetic resonance spectroscopy. Langmuir 15, 2829.

Sofilic, T., Rastovcan-Mioc, A., Cerjan-Stefanovic, S., NovoselRadovic, V., and Jenko, M. (2004). Characterization of steel mill electric-arc furnace dust. J. Hazard Mater. B109, 59.

Stegemann, J. and Côté, P.L. (1990). Report No. WTC-RM-01-89, Canada.

Stegemann, J., Roy, A., Caldwell, R.J., Schilling, P.J., and Tittsworth, R. (2000) Understanding environmental leachability of electric arc furnace dust. I. Environ. Eng. 126, 112.

Tiruta-Barna, L., Imyim, A., and Barna, R. (2004). Long-term prediction of the leaching behavior of pollutants from solidified wastes. Advances Environ. Res. 8, 697.

Van Der Sloot, H.A. (2002). Characterization of the leaching behavior of concrete mortars and of cement-stabilized wastes with different waste loading for long term environmental assessment. Waste Manage. 22, 181.

Van Der Sloot, H.A., Comans, R.N.J., and Hjelmar, O. (1996). Similarities in the leaching behavior of trace contaminants from waste, stabilized waste, construction materials and soils. The Science of the Total Environment. 178, 111. 
